\title{
Mark Naumovich Berdichevskii (April 2, 1923-August 11, 2009)
}

DOI: $10.1134 / \mathrm{S} 1069351309120015$

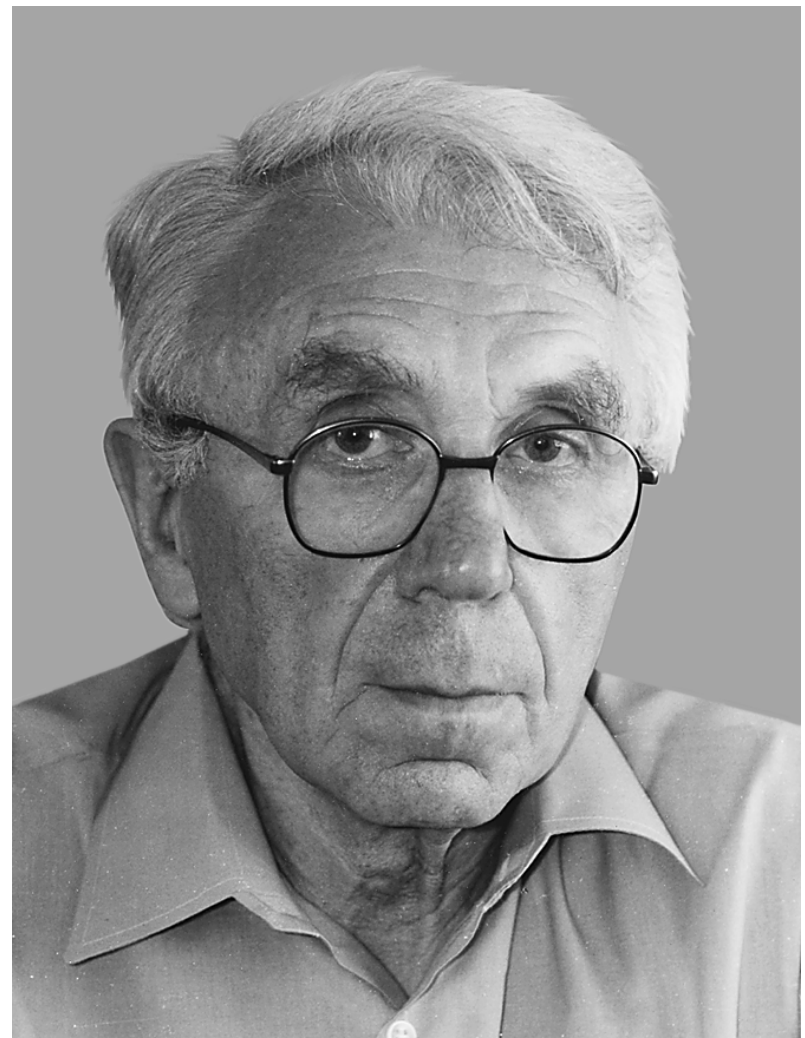

The world of geophysics has suffered a heavy loss-the outstanding geophysicist Mark Naumovich Berdichevskii has died. We shall remember him not only as the founder of many modern fields of modern exploration geophysics, in particular, the method of magnetometallurgic profiling, but also as a patriot of his Motherland-Mark Naumovich lived through the entire Great Patriotic War, from the very first days up to 1945. As a talented man, he was talented in everything.
Mark Naumovich was a member of the circle of young Kiev poets; most of them perished during the war.

We are deeply saddened over the death of a citizen, poet, geophysicist together with the friends and family of Mark Naumovich. The cherished memory of Mark Naumovich will forever be preserved by all those who were lucky to have known him.

The Editorial Board 